\title{
Antalya ilinde tüketicilerin perakendeci markalı süt ve süt ürünleri tercihlerini etkileyen faktörlerin analizi
}

\section{Analysis of factors affecting the preferences of consumers for retailers branded milk and milk products in the Antalya province}

\author{
Yeşim KARAKAYA ${ }^{1}$, Burhan ÖZKAN ${ }^{\circledR}$ \\ ${ }^{1}$ Akdeniz Üniversitesi, Fen Bilimleri Enstitüsü, Tarım Ekonomisi Anabilim Dalı, 07059, Antalya \\ ${ }^{2}$ Akdeniz Üniversitesi, Ziraat Fakültesi, Tarım Ekonomisi Bölümü, 07059, Antalya \\ Sorumlu yazar (Corresponding author): B. Özkan, e-posta (e-mail): bozkan@akdeniz.edu.tr \\ Yazar(lar) e-posta (Author e-mail): yesimkarakaya03@gmail.com
}

\section{MAKALE BILLGISİ}

Alınıș tarihi 22 Ekim 2019

Düzeltilme tarihi 04 Mart 2020

Kabul tarihi 04 Mart 2020

\section{Anahtar Kelimeler:}

Süt tüketimi

Süt ürünleri tüketimi

Market markalı gida

Perakendeci

Antalya

\begin{abstract}
öz
Bu çalıșmanın amacı, Antalya ilinde tüketicilerin perakendeci markalı süt ve süt ürünleri tercihlerini etkileyen faktörlerin analizinin yapılmasıdır. Bu amaçla Antalya ili kentsel alanda basit tesadüfî olasılıklı örnekleme yöntemine göre seçilen 245 tüketici ile anket yapılmıştır. Araştırmada, tüketicilerin demografik ve ekonomik özellikleri ile perakendeci markalı süt ve süt ürünlerinde tüketici tutum ve satın alma davranışı incelenmiştir. Görüşme yapılan tüketicilerin perakendeci markalı süt ve süt ürünleri tercihlerini etkileyen faktörlerin analizinde binary lojistik regresyon analizi kullanılmıştır. Model sonuçlarına göre; tüketicilerin eğitim durumu yükseldikçe perakendeci markalı süt ve süt ürünlerini tüketme etme olasılığı azalmaktadır. Ailedeki birey sayısı arttıkça perakendeci markalı süt ve süt ürünleri tüketim olasılığı artırmaktadır. Kadın tüketici sayısı arttıkça, perakendeci markalı süt ve süt ürünlerinin tüketim olasılığı artmaktadır. Araștırma sonuçlarına göre; tüketicilerin süt ve süt ürünleri tüketiminde perakendeci markalı ürünleri tercih etme eğiliminde oldukları söylenebilir.
\end{abstract}

\section{ARTICLE INFO}

Received 22 October 2019

Received in revised form 04 March 2020

Accepted 04 March 2020

\section{Keywords:}

Milk consumption

Milk products consumption

Market branded food

Retailer

Antalya

\begin{abstract}
The objective of this study was to analyse factors affecting preferences of consumers for retailer branded milk and milk products' in Antalya province, Turkey. In order to achieve this objective, a survey was conducted with 245 consumers selected by using simple random sampling technique in urban area of Antalya. Binary logistic regression analysis was used to examine the demographic and economic characteristics of consumers and consumer attitudes and purchasing behaviors in retailer branded milk and milk products for the study area. In the model, it was obtained that educational level of the consumers, number of individuals in the family and numbers of female consumers had significantly affected the probability of consumption of retailer branded milk and milk products. Among the significant variables, number of individuals in the family and numbers of female consumers had positive effect while the educational level was obtained affecting the probability of consumption negatively. Based on the research results, it can be concluded that consumers tend to prefer retailer branded products in their consumption of milk and milk products.
\end{abstract}

\section{Giriş}

Marka konusu pazarlama disiplininde önemli bir çalışma alanı olup günümüze kadar marka konusunda birçok araştırma yapılmıştır. Pazarlama biliminde, perakendeci markaları ve market markaları, markaya göre daha sonra araştırılmaya başlanmış ve bu konuda bazı araştırmalar yapılmışsa da süt ve süt ürünlerine yönelik özel bir çalışmaya rastlanılmamıştır. Kuşkusuz bunun nedenlerinden biri perakendeci markalarının, markaya göre daha yeni bir kavram olmasıdır. Özel markalı ya da perakendeci markalı ürünler hem üretici hem tüketici açısından çeşitli yararlar sağlamaktadır. Özel etiketli markalı ürünler perakendeciye düşük üretim maliyeti, pahalı olmayan ambalajlama, minimum reklam ve düşük genel üretim masrafları gibi nedenlerle tüketiciye daha ucuz fiyatlarla ürünlerini sunma imkânı yaratmaktadır (Migros Araştırması 2018). 
Perakendeci markalı ürünler tüketici, perakendeci ve üretici açısından son derece yararlıdır. Tüketiciler markalı ürünler tüketmekle; düşük fiyatlı kaliteli ürün satın almak, ürüne kolayca ulaşmak ve satış sonrası güvencesine sahip olmak gibi avantajlar elde etmektedir. Diğer yandan özellikle küçük ve orta ölçekli üretici de sistemli bir şekilde büyüme firsatına ve kendi markasını yaratma şansına sahip olabilmektedir. Perakendecilerin market markalı ürünleri tercih etme nedenleri ise, satış ve kârlarını yükseltmek, müşterileriyle ilişkilerini güçlendirmek ve rakiplerinden daha ucuz ve daha kaliteli ürünler sunarak tercih edilir hale gelmekle birlikte perakendeci imajını geliştirmektir (Demirci Orel 2004).

Perakendeci markalı ürünler, başlangıçta gelişmiş bir teknoloji gerektirmeyen ürünler üzerinde gelişme göstermiştir. $\mathrm{Bu}$ ürünlerin başında meyve-sebze, tahıllar ve raf ömrü uzun ürünler yer almaktadır. Ancak, ilerleyen zaman ve teknolojik gelişmeler marka oluşumunun tamamlanması ile diğer ürün gruplarında da hızlı bir gelişme yaşanmasına neden olmuştur. $\mathrm{Bu}$ ürün grupları, alkollü içecekler, ev eşyaları, evcil hayvan gıdaları ve malzemeleri ile kişisel bakım ürünlerine kadar geniş bir hatta yayılmıştır. Bu çeşitlenmeye rağmen, gıdalar halen en büyük payı almaya devam etmektedir (Albayrak ve Dölekoğlu 2006).

Perakendeci markaları yoğun olarak gıda ürünlerinde artış göstermektedir. Ürünler kategoriksel olarak incelendiğinde süt ve süt ürünlerinde büyük artış görülmektedir. Süt; doğrudan tüketilebildiği gibi, sütten elde edilen yoğurt, ayran, peynir, tereyağı şeklinde de tüketilen ve günlük hayatta ihtiyaç duyulan en önemli besin maddelerindendir. Tüketiciler günlük besin ihtiyaçlarının önemli bir kısmını süt ve süt ürünlerinden karşılamaktadırlar. Bu nedenlerden dolayı, insan hayatının her evresinde süt ve süt ürünleri tüketimi önemli yer tutmaktadır (Gündüz 2013).

Araştırmada Antalya ilindeki tüketicilerin perakendeci markalı süt ve süt ürünleri tercihlerini etkileyen faktörlerin analiz edilmesi amaçlanmıştır. Araştırma konusu ile ilgili daha önce yapılan çalışmalar genellikle perakendeci markalı tüm ürünleri ya da temizlik ürünlerini kapsamıştır. Dolayısıyla bu durum bu çalışmanın yapılmasının gerekliliğini ve özgünlüğünü ortaya koymaktadır. Ayrıca araştırma konusu ile ilgili Antalya ilinde yapılmış herhangi bir çalışmaya rastlanılmamış olması da çalışmanın gerekliliğini arttırıcı bir niteliktir. Diğer yandan perakendeci markalı ürünlerin satışı ve pazarlanması gün geçtikçe artmakta ve market raflarında daha fazla yer almaktadır. Bu nedenlerle Antalya ili kentsel alanda yaşayan tüketicilerin perakendeci markalı süt ve süt ürünleri tüketimini etkileyen faktörlerin belirlenmesinin araştırıcılar, politika belirleyiciler ve ilgili sektör için önemli ve yararlı bulgular sunabilecektir.

\section{Materyal ve Yöntem}

Araştırmanın ana materyalini oluşturan veriler, Antalya kentsel alanda yaşayan tüketiciler ile 2018 yılında yapılan yüz yüze anket yöntemi ile elde edilmiştir. İkincil veriler ise bu alanda daha önce yapılmış ilgili bilimsel çalışmalar, raporlar ve istatistiksel verilerden oluşmaktadır. Araştırmada, örnek hacminin belirlenmesinde tüketici araştırmalarında en çok kullanılan yöntem olan "Basit Tesadüfî Olasılıklı Örnekleme Yöntemi” kullanılmıştır (Kurtuluş 1998). Ana kütlenin nicelik itibariyle iki gruba bölündüğü durumlarda ve ana kütle büyüklüğünün 500000 den fazla (Antalya merkez ilçeleri nüfusu toplamı: 1158863) olması koşulunda \%95 güven sınırları ve $0.25(0.5 * 0.5)$ varyans için hesaplanan örnek büyüklüğü hesaplanmaktadır. $\mathrm{Bu}$ kapsamda görüşme yapılan örnek hacmine ulaşmak için yürütülen ön anket çalışmasında, Antalya ili kentsel alan (Muratpaşa, Konyaaltı, Kepez) hane halkının $\% 80$ 'inin perakendeci markalı ürün satın aldığı, bu ortalama $\% 50$ oranının +0.05 yanılabileceği ve bu sınırların $\% 95$ güvenilir olması varsayımıyla görüşme yapılan tüketici sayısı (hane halk1) 245 olarak belirlenmiştir.

$n=\left(\frac{z x^{2}}{d}\right) P \cdot Q$

Formülde;

n: Örneklem hacmi,

P: İncelenen birimin kitle içinde gerçekleşme olasılığını (perakendeci markalı süt ve süt ürünü satın alan tüketicilerin oranı $\% 80$ ),

Q: 1-P (perakendeci markalı gıda ürünleri satın almayan tüketicilerin oran1 $\% 20$ ),

$Z x^{2}$ : Güven aralığını (\%95, tablo değeri 1.96),

d: Hata terimini (\%5) ifade etmektedir.

Çalışmada kullanılacak örnek büyüklüğünün $\mathrm{N}$ kütle içindeki oranının $\% 5$ en büyük olup olmadığı ise test edilmiştir $(\mathrm{n} / \mathrm{N} \geq 0.5)$. Buna göre Antalya ili kentsel alanda = $245 / 1.158 .863=00021<0.05$ küçük ve anlamlı olduğu bulunmuştur.

\subsection{Verilerin analizi aşamasında izlenen yöntem}

Araştırma kapsamında derlenen veriler lojit regresyon model kullanılarak analiz edilmiştir. Lojit modelinde bağımlı değişken binominal olup tahmin edilen olasılık değerleri 0 ile 1 arasında değişmektedir. Çalışmada kullanılabilecek yöntemlerden birisi de Probit modeli olmakla birlikte, lojit modelinde bağımsız değişkenlerin bağımlı değişkeni daha iyi açıkladığı kabul edildiği kabul edilmektedir (Amemiya 1985). Ayrica, temel verilerin hane halklarından anket yolu ile elde edilen veriler olması nedeniyle en yüksek olabilirlik metodunun kullanılmasının daha iyi sonuç vereceği düşünülmüştür (Gujarati 1995). En yüksek olabilirlik metodu kullanmanın en önemli avantajlarından birisi bu metodun kullanılmasıyla elde edilen parametrelerin tutarlı ve etkin olmasidır (Pindyrk ve Rubinfeld 1991).

Kümülâtif logistik dağılım fonksiyonuna bağlı olan lojit modeli aşağıdaki şekilde ifade edilmektedir (Gujarati 1995).

$$
p_{i}=\frac{1}{\left(1+\exp ^{-\left(\varepsilon^{i}\right)}\right)}
$$

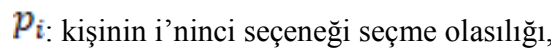

$$
z_{i}=a+\beta x_{i}
$$

Formülde;

$$
\begin{aligned}
& \text { a: sabit katsayı } z_{i}=\log \\
& \beta: \text { tahmin edilen parametreler } \\
& x_{n}: n^{\prime} \text { inci bağlmsı değişken }
\end{aligned}
$$


Yukarıdaki denklemin yeniden düzenlenmesi ve eşitliğin iki tarafının logaritmasının alınması ile aşağıdaki denklem elde edilmektedir.

$$
\frac{p i}{(1-p i)}=a+\beta_{1} x_{1}+\beta_{2} x_{2}+\cdots \cdots \cdots+\beta_{n} x_{n}+e
$$

$\mathrm{Bu}$ regresyon modelinde bağımlı değişken $\mathrm{Zi}$, "e"' hata terimini ifade etmektedir.

\section{Bulgular ve Tartışma}

Görüşme yapılan tüketicilerin yaş, cinsiyet, eğitim durumu, hanedeki birey sayısı, hane geliri gibi demografik değişkenler pazarlama araştırmalarında önem taşımaktadır. Peterson (2005)'e göre tüketim eğilimlerinde ve satın alınacak marka veya ürün tercihlerinde cinsiyetin oynadığı rol ve yaptığı etki son derece önemlidir. Bir malın satın alınması hususunda erkeklerin karar verici olduğu veya kadınların söz sahibi olduğu durumlar bulunmaktadır (Kocabaş ve ark. 1999).

Araştırma kapsamında görüşme yapılan 245 tüketicinin yaş ortalamas1 38,1 olup tüketicilerin $\% 35.1$ 'i $21-31$ yaş aralığındadır. Görüşme yapılan tüketicilerin $\% 80.4$ 'ü kadın, \%19.6'sı erkektir. Tüketicilerin eğitim seviyesine bakıldığında ise \%10.2'sinin ilköğretim mezunu, \%20'si lise mezunu, $\% 29.4$ 'ü lisans mezunu olduğu belirlenmiştir. Tüketicilerin \%56.7'si evli (çocuklu) ve \%29.4'ü bekârdır (Çizelge 1).

Tüketici kararlarını etkileyen faktörler incelendiğinde, ailedeki birey sayısı, çalışan sayısı ve çocuk sayısının büyük ölçüde etkili olduğu görülmektedir. Bu bağlamda görüşme yapılan hanelerin \%7.8'i tek kişi, \%13.5'i iki kişi olup, \%35.9'u dört kişi ve \%27.8'i üç kişilik bir aileden oluştukları belirlenmiştir. Görüşme yapılan tüketici hanelerinde 5 ve üzeri aile bireyine sahip olanların oranı ise $\% 15$ 'tir. Hanede yaşayan 18 yaşın altındaki çocuk sayısı incelendiğinde; \%29.8'inin iki çocuğu bulunmaktadır. Ayrıca hanelerin \%53.1'inde sadece bir kişi çalışırken, \%39.6'sında ise iki kişi çalışmaktadır \% (Çizelge 1).

Tüketicilerin perakendeci markalı süt ve süt ürünleri tercihlerini etkileyen faktörlerin analizinde binary lojistik regresyon analizi kullanılmıştır. Uygulanan lojistík regresyon modelinde bağımlı değişkeni, araştırmaya katılan tüketicilerin "Perakendeci markalı süt ve süt ürünleri tüketiyor musunuz?" sorusuna verdikleri "Evet", "Hayır" cevaplarından oluşmaktadır. Perakendeci markalı gıda ürünü tüketenler için bağımlı değişken 1, tüketmeyenler için 0'dır. Modelin değişkenleri Çizelge 2'de verilmiştir.

Lojistik regresyon analiz sonuçları Çizelge 3'de sunulmuştur. Analiz sonuçlarına göre; cinsiyet değişkeni istatistiksel olarak anlamlı olup kadın tüketicilerin erkek tüketicilere göre perakendeci markalı süt ve süt ürünlerini tüketme olasılığ 5.84 kat daha fazla olduğu tespit edilmiştir $(\mathrm{p}<0.01)$. Eğitim durumu ise istatistiksel olarak anlamlı ve negatif yönlü bir ilişki bulunmuştur. Buna göre kişilerin eğitim düzeyi arttıkça perakendeci markalı süt ve süt ürünleri tüketme oranı azalmaktadır. Hatipoğlu (1993)'na göre eğitim düzeyi yükseldikçe tüketiciler alışveriş tercihlerinde daha fazla seçici olmakta, seçebileceği daha fazla ürün çeşidini aramak ve daha kaliteli ürünler satın almak istemektedirler. Tek (1999)'e göre de kişilerin eğitim seviyeleri, meslekleri ve çalışma alanları satın alacakları ürün ve hizmetlerde büyük ölçüde etkilidir.
Çizelge 1. Tüketicilerin demografik özelliklerine göre dağılımı.

Table 1. Distribution of consumers by demographic characteristics.

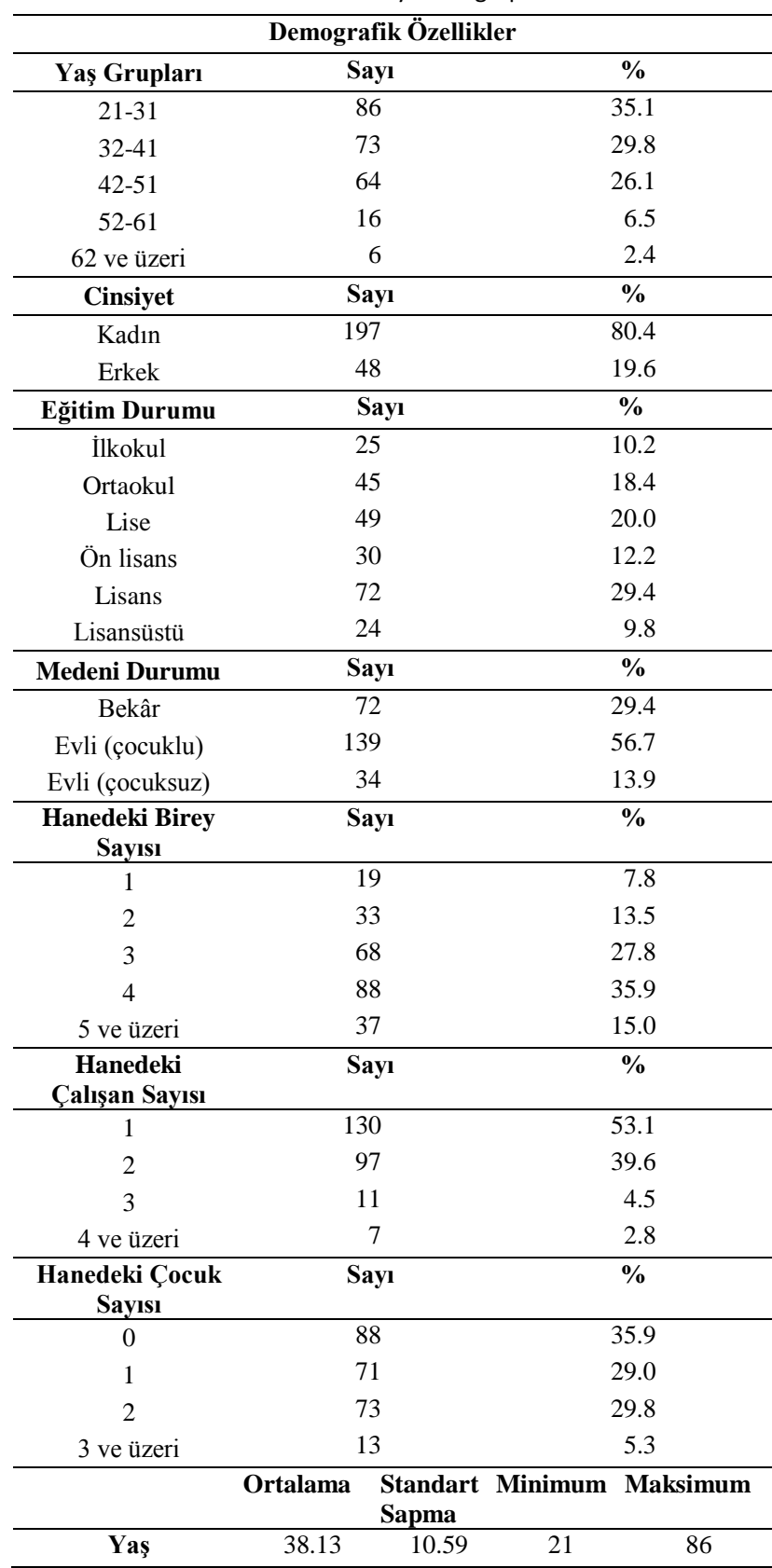

Ailedeki birey sayısı incelendiğinde \%5 önem seviyesinde istatistiksel olarak anlamlı ve pozitif yönlü bir ilişki olduğu belirlenmiştir. Dolayısıyla ailedeki birey sayısındaki her bir kişilik artış perakendeci markalı süt ve süt ürünleri tüketme olasılığını 1.64 kat arttırmaktadır.

Perakende markaları, özel markaların ucuz bir taklidi olarak ortaya çıkan ve daha çok satın alma gücü düşük tüketici kesiminin ihtiyacını karşılamak amacıyla üretilen ürünlerdir. (Özgül 2004) ve yapılan diğer çalışmalarda genellikle perakendeci markalı ürün tercihinin gelir ile negatif yönlü bir ilişkisi olduğunu belirtmişlerdir. Akpınar (2004) Antalya ilinde yaptığı çalışmasında market markalı gıda ürünleri tüketici kesiminin orta ve orta-alt gelir grubunun oluşturduğunu 
Çizelge 2. Lojistik model için bağımlı ve bağımsız değişkenler.

Table 2. Dependent and independent variables for logistic model

\begin{tabular}{ccc}
\hline Değişken Türü & Değişken Adı & Tanımlar ve Kodlar \\
\hline Bağımlı Değişken & Perakendeci Markalı Süt ve Süt Ürünleri Tüketen & $1=$ Tüketen, $0=$ Tüketmeyen, \\
\hline & Cinsiyet & $1=$ Erkek, $2=$ Kadın \\
Bağımsız & Eğitim Durumu & 1= İlkokul, $2=$ Ortaokul, $3=$ Lise, $4=$ Ön Lisans, $5=$ Lisans, $6=$ Lisansüstü \\
Değişkenler & Ailedeki Birey Sayısı & Kişi \\
& Aylık Gelir & TL/ay \\
& Süt ve Süt Ürünleri Fiyat Durumu & $0=$ Çok pahalı, $1=$ Pahalı, 2= Normal, 3= Ucuz \\
\hline
\end{tabular}

Çizelge 3. Lojistik regresyon analizi sonuçları.

Table 3. Logistic regression analysis results.

\begin{tabular}{|c|c|c|c|c|c|c|}
\hline \multicolumn{7}{|c|}{ Bağımlı Değişken: Perakendeci Markalı Süt ve Süt Ürünleri Tüketen } \\
\hline \multicolumn{2}{|c|}{ Bağımsız Değişkenler } & Kat Sayı & Standart Hata & Wald Değeri & $\mathbf{P}$ & Olasılık Oranı \\
\hline \multirow{2}{*}{ Cinsiyet } & Erkek (referans) & - & - & - & - & - \\
\hline & Kadın & 1.765 & 0.460 & 14.711 & $0.001 * * *$ & 5.844 \\
\hline \multirow{6}{*}{ Eğitim Durumu } & İlkokul (referans) & & & & & \\
\hline & Ortaokul & -2.254 & 1.108 & 4.134 & $0.042 * *$ & 0.105 \\
\hline & Lise & -2.599 & 1.113 & 5.451 & $0.020 * *$ & 0.074 \\
\hline & Önlisans & -2.967 & 1.177 & 6.359 & $0.011^{* *}$ & 0.051 \\
\hline & Lisans & -1.509 & 1.185 & 1.623 & 0.203 & 0.221 \\
\hline & Lisansüstü & -2.792 & 1.309 & 4.546 & $0.032 * *$ & 0.061 \\
\hline Birey & Ailedeki Birey Sayısı & 0.492 & 0.237 & 4.315 & $0.038 * *$ & 1.636 \\
\hline Gelir & Aylık Gelir & -0.001 & 0.000 & 6.145 & $0.013 * *$ & 1.004 \\
\hline \multirow{5}{*}{$\begin{array}{c}\text { Süit Ürünleri } \\
\text { Fiyatlarının } \\
\text { Değerlendirilmesi }\end{array}$} & Çok Pahalı(ref) & - & - & - & - & - \\
\hline & Pahalı & -0.304 & 0.518 & 0.343 & 0.558 & 0.738 \\
\hline & Normal & -1.103 & 0.514 & 4.608 & $0.031 * *$ & 0.332 \\
\hline & Ucuz & 0.107 & 0.794 & 0.018 & 0.893 & 1.113 \\
\hline & Sabit Terim & -0.723 & 1.799 & 0.161 & 0.688 & 0.485 \\
\hline \multicolumn{7}{|c|}{ Model Özeti: -2 Log olabilirlik $=247.882$, Cox $\&$ Snell $R^{2}=0.310$} \\
\hline \multicolumn{7}{|c|}{ Nagelkerke $\mathrm{R}^{2}=0.414, \chi 2=91.070$, Anlamlılık Düzeyi $=0.001$} \\
\hline \multicolumn{7}{|c|}{$\mathrm{p}<* * 0.05 \mathrm{p}<* * * 0.01$} \\
\hline
\end{tabular}

belirtmiştir. $\mathrm{Bu}$ sonuçları göre gelir seviyesi arttıkça tüketicilerin perakendeci markalı ürünlere yönelimi azaltmaktadır. Hanelerin aylık gelirleri incelendiğinde istatistiksel olarak anlamlı olduğu belirlenmiştir. Hanede ki kişilerin aylık gelirlerindeki her bir birimlik artış perakendeci markalı süt ve süt ürünleri tüketme olasılığını 1.01 kat azaltmaktadır. $(\mathrm{p}<0.05)$. Süt ve süt ürünlerine ilişkin fiyat değerlendirmesi değişkeni incelendiğinde istatistiksel olarak anlamlı negatif yönlü bir ilişki olduğu belirlenmiştir $(\mathrm{p}<0.05)$. $\mathrm{Bu}$ sonuç, süt ve süt ürünlerini çok pahalı bulanlara oranla normal bulanların perakendeci marka süt ve süt ürünlerini tüketme olasıllı̆ının 0.33 kat daha az olduğunu belirtmektedir.

Modelin -2log olabilirlik değeri 247.882 olduğu saptanmıştır. Model için uyum iyiliği ölçüsü olarak kullanılan $\mathrm{R}^{2}$ değerlerinden Nagelkerke indeksi Cox-Snell indeksine maksimum değere göre bir düzeltme yapmakta ve daha büyük değer çıkmaktadır. Buna göre modelin perakendeci marka süt ve süt ürünleri tüketme durumlarını açıklama oranı \%41.4'tür (Çizelge 3).

\section{Sonuc ve Öneriler}

$\mathrm{Bu}$ çalışmanın amacı Antalya ilinde tüketicilerin perakendeci markalı süt ve süt ürünleri tercihlerini etkileyen faktörlerin analizinin yapılmasıdır. $\mathrm{Bu}$ amaçla Antalya ili kentsel alanda basit tesadüfî olasılıklı örnekleme yöntemine göre seçilen 245 tüketici ile 2018 y1lında yüz yüze anket yapılmıştır. Görüşme yapılan tüketicilerin perakendeci markalı süt ve süt ürünleri tercihlerini etkileyen faktörlerin analizinde binary lojistik regresyon analizi kullanılmıştır. Araştırma kapsamında tüketicilerin demografik ve ekonomik özellikleri ile perakendeci markalı süt ve süt ürünlerinde tüketici tutum ve satın alma davranışları da incelenmiştir.

Araştırmaya katılan 245 tüketicinin yaş ortalaması 38.1 olup tüketicilerin \%80.4'ü kadın, \%19.6's1 erkek olduğu belirlenmiştir. Tüketicilerin süt ve süt ürünlerini satın alırken tercihlerini etkileyen nedenler incelendiğinde; \%25'i kişisel isteklerine göre tercih ettiklerini, \%32'si kendi deneyimlerinin önemli olduğunu ve \%19'u ise aile üyelerinin istekleri doğrultusunda tercih ettiklerini belirtmişlerdir. Görüşme yapılan tüketicilerin \%52.3'ünün perakendeci markalı süt ve süt ürünü satın aldığı, \%47.7'sinin ise satın almadığ belirlenmiştir. Bu sonuçlara göre araştırma bölgesinde ve perakendeci markalı ürünlere talebin fazla olduğu ifade edilebilir. Araştırma sonuçlarına göre kadın tüketicilerin erkek tüketicilere oranla perakendeci markalı süt ve süt ürünleri tüketme ve satın alma oranları daha yüksektir. Buna göre süt ve süt ürünleri satın alma aşamasında kadınların karar vermede daha aktif rol oynadıkları görülmektedir.

Tüketicilerin perakendeci markalı süt ve süt ürünleri tercihlerini etkileyen faktörlerin analizi için kullanılan lojistik regresyon analizinde perakendeci markalı süt ve süt ürünlerini tüketenler/tüketmeyenler bağımlı değişken olarak alınmıştır. Tüketme olasılığını etkileyen faktörleri belirleyebilmek için 
modele on iki değişken katılarak istatistiki olarak test edilmiştir. Uygulanan lojistik regresyon analiz sonuçlarına göre beş değişken istatistiki olarak anlamlı bulunup yorumlanmıştır. Model sonuçlarına göre; tüketicilerin eğitim durumu yükseldikçe perakendeci markalı süt ve süt ürünlerini tüketme olasılığı azalmaktadır. Ailedeki birey sayısı arttıkça perakendeci markalı süt ve süt ürünleri tüketim olasılığı artırmaktadır. Kadın tüketici sayısı arttıkça, perakendeci markalı süt ve süt ürünlerinin tüketim olasıllğı artmaktadır. Sonuç olarak; tüketicilerin süt ve süt ürünleri tüketiminde perakendeci markalı ürünleri tercih etme eğiliminde oldukları söylenebilir. Perakendeci markalı süt ve süt ürünleri tüketiciler için ucuz birer alternatif oluştururken, diğer taraftan marketlere kâr ve müşteri sağlamaktadır. Üreticiler için perakendeci markalı süt ve süt ürünü üretmek avantaj sağladığı gibi dezavantaj da sağlayabilmektedir. Üreticilerin üretim kapasitelerini, piyasa şartlarını ve perakendeci markası üretmekle elde edecekleri tüm avantaj ve dezavantajları iyi belirlemesi ve değerlendirmesi gerekmektedir.

\section{Kaynaklar}

Akpınar MG (2004) Market (süpermarket-hipermarket) markalı gıda ürünleri tüketici pazarının analizi: Antalya ili uygulaması. Çukurova Üniversitesi, Fen Bilimleri Enstitüsü, Tarım Ekonomisi Anabilim Dalı, Doktora Tezi, Adana.

Albayrak M, Dölekoğlu C (2006) Gıda perakendeciliğinde market markalı ürün stratejisi. Akdeniz İktisadi ve İdari Bilimler Fakültesi Dergisi 11: 204-218.

Amemiya T (1985) Advanced econometrics. Cambridge, MA: Harvard University Press.

Demirci Orel F (2004) Market markaları ve üretici markalarına yönelik tüketici algılamaları. Çukurova Üniversitesi Sosyal Bilimler Enstitüsü Dergisi 13(2).

Gujarati DN (1995) Basic econometrics. McGraw-Hill, Inc. New York.

Gündüz O (2013) Süt ve süt ürünleri tüketiminde tüketici tercihlerini etkileyen faktörler: Samsun ili örneği. Gıda Teknolojileri Elektronik Dergisi 8(1): 45-52.

Hatipoğlu Z (1993) Temel pazarlama. Beta Yayın Dağıtım, İstanbul, s. 38.

Kurtuluş K (1998) Pazarlama araştırmaları. Avcıol Basım Yayın, Genişletilmiş Altıncı Baskı, İstanbul.

Kocabaş F ve ark. (1999) Reklam ve halkla ilişkilerde hedef kitle. İletişim Yayınları, İstanbul, s. 214.

Migros araştırması (2018) http://slideplayer.biz.tr Erişim 30 Aralık 2018.

Özgül E (2004) Özel marka üretiminde üretici perakendeci ve bağımlılığının işbirliği süreç ve performansa etkileri. Dokuz Eylül Üniversitesi İktisadi İdari Bilimler Fakültesi, İşletme Bölümü. Ege Akademik Değerlendirme Dergisi 4(1): 144155.

Peterson RA (2005) Response construction in consumer behavior research. Journal of Business Research 58(1): 348-353.

Pindyrk R, Rubinfeld D (1991) Econometric moldels and economic forecasts. McGraw-Hilll, Inc, New York, USA

Tek ÖB (1999) Pazarlama ilkeleri. Beta Yayınları, 8. Baskı, İstanbul. 